\title{
Direct Determination of Magnesium at the $1 \%$ Level in Solid Samples by Graphite Furnace Atomic Absorption Spectrometry
}

\author{
Miguel A. Belarra ${ }^{\dagger}$, Isela Lavilla and Juan R. Castillo \\ Department of Analytical Chemistry, University of Zaragoza, \\ E-50009 Zaragoza, Spain
}

\begin{abstract}
Magnesium can be determined at levels above $1 \%$ in poly (vinyl chloride) (PVC) by direct analysis of the solid sample using graphite furnace atomic absorption spectrometry (GFAAS) and working at the $383.4 \mathrm{~nm}$ line. The analytical conditions used permit the determination of magnesium at a concentration of $2 \%$ by interpolation on a calibration graph run for the aqueous solution. No special sample introduction system, platform or matrix modification is required. The relative standard deviation thus achieved is $c a .7 \%$.
\end{abstract}

Keywords Poly(vinyl chloride) analysis, direct analysis, solid sample, magnesium determination, graphite furnace atomic absorption spectrometry

The choice of an analytical method for a given purpose is currently not always dictated by accuracy alone, but also often by throughput, economy and miscellaneous factors. ${ }^{1}$ Graphite furnace atomic absorption spectrometry (GFAAS) is in principle a suitable analytical technique for direct determination of metals in solid samples as it meets the typical requirements of chemical analysis for industrial product control; ${ }^{2}$ in fact, it provides reliable results in a fairly short time, which is often more important than high precision.

However, this analytical technique has seldom been used so far in industrial analysis, except in Germany, where Zeeman-AAS routinely employs it for processes of industrial product control. ${ }^{3}$ Also, while direct determinations of metals in solid samples by GFAAS have been around for over 20 years, they have not gained wide popularity, as reflected in the scarcity of literature on the topic (only about 10 papers per year). ${ }^{4}$

The information typically supplied in papers reporting GFAAS applications involving solid samples may have been a deterrent for expanding use to non-dissolved samples. Thus, (1) introduction of solid samples seems to be technically more difficult and entails purchasing dedicated equipment; ${ }^{5}$ (2) in many instances, determinations are hindered by major matrix interferences that call for Zeeman correction background; 6 and (3) proper calibration is far from easy..$^{7,8}$ In short, direct determinations of metals in solid samples by GFAAS are seemingly cumbersome and necessitate additional investments in instrumentation and skilled operators. Also, it is imprecise by analytical standards (relative standard

$\dagger$ To whom correspondence should be addressed. deviations for this technique are rarely better than $10 \%) .{ }^{9}$

Moreover, most published papers on the topic include no clear, detailed description of the determinative procedure, so that it can be reproduced by other analysts. The assertion by Esser ${ }^{3}$ that "the task for the analytical chemist in this situation must not only be to check the capabilities and limits of solid sampling AAS for the present-day problems but to transfer his knowledge into practice" is highly pertinent in this context.

In this way, useful effective methods for direct determination of metals in solid samples by GFAAS would meet the following requirements: (1) easy sample introduction without special instrumentation (occasionally through the central sampling hole in the graphite tube); ${ }^{10-12}$ (2) use of basic GFAAS equipment, i.e., without commercial solid sampler or Zeeman background corrector; (3) the ability to use aqueous solutions for calibration; (4) easy to follow and reproducable procedures providing relative standard deviations below $10 \%$.

While these requirements are rather difficult to meet in broad terms, one can indeed develop simple methods for some specific purposes, such as analysis of nonpulverulent samples whose matrices are relatively easily destroyed in charring. ${ }^{13,14}$

One other problem faced in extending use of GFAAS to direct determinations of metals in solid samples arises from over-sensitivity. Thus, few applications ${ }^{15-19}$ allow metal contents between 0.1 and $1 \%$ (rather common place for products of industrial interest) to be determined. According to Carnick et al. ${ }^{16}$ and Baxter and Frech ${ }^{8}$, this frequently mentioned problem can be overcome by using less sensitive lines, an argon stream during measure- 
ments, diluted samples or a controlled atomization temperature.

Notwithstanding the many metals have been determined by GFAAS in a wide variety of solid samples ${ }^{4}$, relatively few applications have been devoted to magnesium ${ }^{20-23}$, a likely result of this excessive sensitivity. Thus, the usual lines at 285.2 and $202.5 \mathrm{~nm}$ are too sensitive, even at magnesium contents of $c a .0 .001 \%$. Berggren, who used as little as $1-15 \mu \mathrm{g}$ of sample, suspended pancreatic tissue samples in $50 \mu \mathrm{l}$ of water to determine magnesium; ${ }^{20}$ however, the problem is more frequently addressed by diluting the sample with graphite. ${ }^{21,22}$ In this respect, Page et al. ${ }^{21}$ found the addition of graphite to improve the resulting signal, through its reductant character.

This paper reports a GFAAS method for the determination of magnesium at concentrations above $1 \%$ in poly(vinyl chloride) samples, calling for no skilled operator or special equipment. Magnesium oxide is added to PVC as a flame retardant and also as a filler to reduce cost in rigid PVC formulations.

\section{Experimental}

\section{Apparatus}

A Perkin-Elmer Model 3030 atomic absorption spectrometer, equipped with a microprocessor, a monitor and a printer, was used together with a PerkinElmer HGA-400 graphite furnace furnished with a temperature programmer and an autosampler (PerkinElmer AS40). A deuterium lamp was needed to correct non-especific absorption. Unpyrolytic graphite tubes whose bors were mechanically enlarged to $c a .4 \mathrm{~mm}$ were used.

Flame-AAS measurements were made on a PerkinElmer Model 2380 atomic absorption spectrometer using a hollow cathode lamp purchased from GBC.

\section{Reagents \\ Magnesium standard, $10 \mathrm{mg} \mathrm{ml}^{-1}$. Weigh an amount of $1.00 \mathrm{~g}$ of metal magnesium to within $0.0001 \mathrm{~g}$ and dissolve it in $1+1 \mathrm{v} / \mathrm{v}$ hydrochloric acid. Then, transfer the solution quantitatively to a $100-\mathrm{ml}$ volumetric flask and dilute to volume with distilled water.}

Polyvinyl chloride resin and real sample. A commercially available PVC sample with a magnesium content provided by the manufacturer (Cables de Comunicaciones) of $c a .2 \%$ was used.

All stock solutions were prepared from analyticalgrade reagents. More dilute solutions of magnesium were made as required by diluting the stock solution with distilled water immediately before use.

\section{Flame- $A A S$ procedure}

The procedures used to treat PVC samples and determine magnesium by flame-AAS were described in detail elsewhere. ${ }^{24}$
Table 1 Instrumental parameters used in the determination of magnesium by GFAAS

\begin{tabular}{|c|c|c|c|}
\hline \multicolumn{2}{|c|}{ Wavelength/nm } & \multicolumn{2}{|c|}{383.4} \\
\hline \multicolumn{2}{|c|}{ Intensity/mA } & \multicolumn{2}{|c|}{10} \\
\hline \multicolumn{2}{|c|}{ Slit width/nm } & \multicolumn{2}{|c|}{0.7} \\
\hline \multicolumn{2}{|c|}{ Gas flow-rate $/ \mathrm{ml} \mathrm{min}^{-1}$} & \multicolumn{2}{|c|}{300} \\
\hline \multicolumn{2}{|c|}{ Working range $/ \mu \mathrm{g}$} & \multicolumn{2}{|c|}{$0-80$} \\
\hline \multicolumn{2}{|c|}{ Injected volume/ $\mu \mathrm{l}$} & \multicolumn{2}{|c|}{20} \\
\hline \multicolumn{2}{|c|}{ Sample mass/mg } & \multicolumn{2}{|c|}{$1.0-3.5$} \\
\hline Step & Temperature $/^{\circ} \mathrm{C}$ & $\mathrm{Ramp} / \mathrm{s}$ & Hold time/s \\
\hline Drying & 120 & 20 & 30 \\
\hline Charring & 900 & 6 & 20 \\
\hline Atomization & 2400 & 0 & 3 \\
\hline Cleaning & 2700 & 1 & 3 \\
\hline
\end{tabular}

\section{Solid sampling procedure}

The PVC sample was homogenized and rolled to a sheet of $c a .12 \times 14 \mathrm{~cm}$ and $2-\mathrm{mm}$ thick. From the sheet, small pieces at roughly the required mass were cut off by using stainless-steel scissors, while handling the plastic with stainless-steel pincers. The PVC pieces were weighed to within $1 \times 10^{-5} \mathrm{~g}$. Samples of $0.5-5 \mathrm{mg}$ were used in different experiments.

Calibration graphs were run by using standard aqueous solutions of magnesium containing the concentrations given in Table 1. Each measurement was made three times.

An amount of $c a .1 .0-3.5 \mathrm{mg}$ solid PVC sample was directly introduced into a pyrolytic graphite tube through an inverted paper cone with its apex pierced; this cone was inserted into the enlarged hole of the tube. The magnesium content in the sample was calculated by interpolation on the pertinent calibration graph.

\section{Measurement conditions}

Solutions and real samples were atomized electrothermally under the same conditions and both nonspecific absorption and the atomic absorption of magnesium were measured under the working conditions shown in Table 1. All measurements were made in the integrated absorbance mode without halting the flow in the atomization step.

\section{Results and Discussion}

\section{Selection of the working wavelength}

As noted before, the lines generally used to determine magnesium by GFAAS in solid samples (285.2 and $202.5 \mathrm{~nm}$ ) are too sensitive for the intended purpose, even if the metal is present at a very low concentration. It is not easy to find alternative suitable lines for this element (none of the transitions in the singlet state seem to fit). Thus, we tested the line at $383.8 \mathrm{~nm}$, corresponding to a triplet transition. The results obtained are given in Table 2 as the approximate magnesium content in the sample obtained by placing $c a .3 \mathrm{mg}$ of sample into the 
Table 2 Results provided by various wavelengths

\begin{tabular}{cllll}
\hline $\begin{array}{c}\text { Wavelength/ } \\
\mathrm{nm}\end{array}$ & $\begin{array}{c}\text { Mass } \\
\text { range/ } \\
\mu \mathrm{g}\end{array}$ & $\begin{array}{c}\text { Limit of } \\
\text { detection/ } \\
\mu \mathrm{g}\end{array}$ & $\begin{array}{c}\text { Correlation } \\
\text { coefficient }\end{array}$ & $\begin{array}{c}\text { Magnesium } \\
\text { content of the } \\
\text { sample, \% }\end{array}$ \\
\hline 202.6 & $0-0.003$ & 0.0002 & 0.9994 & 0.0001 \\
285.2 & $0-0.02$ & 0.0015 & 0.9987 & 0.0005 \\
383.4 & $0-80$ & 1.8 & 0.9989 & 2 \\
\hline
\end{tabular}

atomizer. As can be seen, this line is far less sensitive than the 285.2 and $202.5 \mathrm{~nm}$ lines, so it is appropriate for magnesium contents above $1 \%$. In addition, it results in a wide linear concentration range and a correlation coefficient similar to those for the more sensitive lines.

\section{Study of the atomization conditions}

The electrothermal atomization procedure was optimized by using an aqueous solution of magnesium. The results obtained are given as averages of three consecutive measurements made at a reading time of $3 \mathrm{~s}$ without halting the flow in the atomization step.

Preliminary measurements made by using a pyrolytic coated graphite tube provided magnesium signals that increased significantly with the tube usage. If the tube was new, signals were tailed; however, as usage increased, signals were better defined and the absorbance increased.

This problem was solved by using unpyrolytic tubes, with which the signal was independent of usage, as shown in Fig. 1. Some magnesium determinations in solid samples by GFAAS use graphite, yet their proponents failed to mention the above described difficulty as the reason for their choice. Koshino and Narukawa ${ }^{23}$ used a graphite sample while others use graphite to dilute the sample $^{22}$ or improve the analytical signal. ${ }^{21}$

The charring temperature is very important, as it must ensure efficient matrix removal, with no loss of magnesium. Matrix destruction was complete in practice if a charring temperature above $650^{\circ} \mathrm{C}$ was applied for $20 \mathrm{~s}$. However, some magnesium was lost below $1000^{\circ} \mathrm{C}$, as can be seen in Fig. 2. Therefore, a charring temperature of $900^{\circ} \mathrm{C}$ was used for $20 \mathrm{~s}$.

As can also be seen from Fig. 2, the atomization temperature had a decisive influence on the integrated absorbance: above $2000^{\circ} \mathrm{C}$, the absorbance increased linearly with the atomization temperature. This can be ascribed to the non-resonance line ${ }^{25}$ use; however, Muñoz et al. ${ }^{22}$, who used the 202.5-nm line, found a similar dependence. A $2400^{\circ} \mathrm{C}$ atomization temperature was finally chosen because the resulting measured absorbance was appropriate for the amount of magnesium in the sample.

On the other hand, the integrated absorbance measured from aqueous solutions of magnesium in the presence and absence of PVC resin was identical. Therefore, correct calibration was achieved by using aqueous solutions of the metal.

The integrated absorbance decreased after several

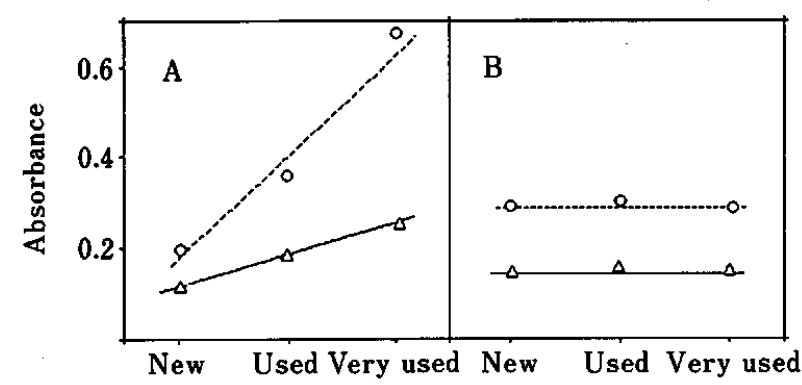

Fig. 1 Variation of the absorbance with tube usage: A, pyrolitic graphite tube; B, unpyrolitic graphite tube (solid line, peak area; broken line, peak height).

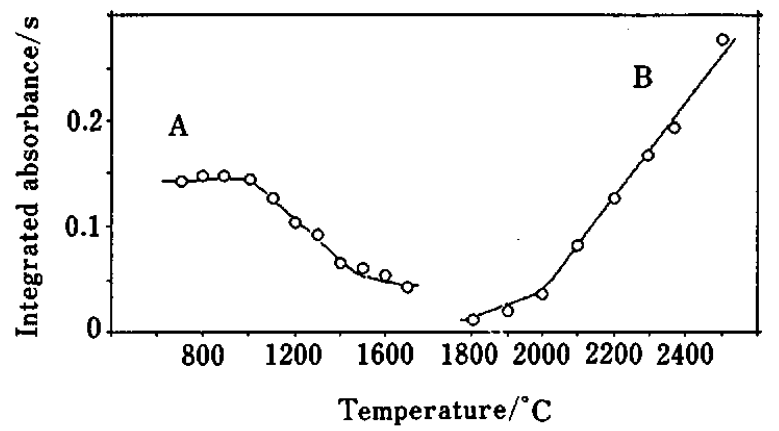

Fig. 2 Optimization of the charring (A) and atomization (B) temperature.

PVC samples were successively atomized, as a result of negative non-specific absorption. This can be ascribed to sample residues building up in the tubes that were visually perceptible after introduction of about ten samples. The effect of such residues was quite small and easy to correct by the deuterium lamp for the first few samples; however, the effect was quite significant after the sixth sample, so the tube must be cleaned after processing every six samples.

\section{Calibration}

In order to fully optimize the measurement conditions, the magnesium signals obtained under the abovedescribed conditions have been studied. Figure 3 shows the signals obtained for a $3000 \mu \mathrm{g} \mathrm{ml}^{-1} \mathrm{Mg}(\mathrm{II})$ solution $(60 \mu \mathrm{g}$ of magnesium) and a solid sample of $3 \mathrm{mg}(60 \mu \mathrm{g}$ of magnesium), measured under the final conditions. As can be seen, the two signals were quite similar. Nevertheless, we chose to use peak area measurements.

By using an aqueous solution of magnesium under the optimal atomization conditions, the equation for the calibration graph was established by the method of leastsquares; integrated absorbance $=0.0021 \mu \mathrm{g}$ of $\mathrm{Mg}-$ 0.0003 . The correlation coefficient was greater than 0.99 .

\section{Analytical results}

In order to study the influence of the different 


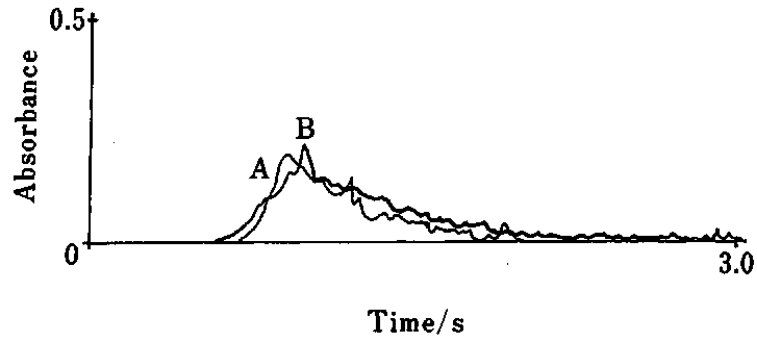

Fig. 3 Typical peaks for magnesium: A, $60 \mu \mathrm{g}$ magnesium in water; $B, 3.0 \mathrm{mg}$ of solid sample ( $60 \mu \mathrm{g}$ of magnesium).

Table 3 Preliminary results obtained in the determination of magnesium

\begin{tabular}{lcc}
\hline \multicolumn{1}{c}{ Parameter } & $\begin{array}{c}\text { All } \\
\text { measurement }\end{array}$ & $\begin{array}{c}\text { Without } \\
\text { outlier }\end{array}$ \\
\hline Number of determinations & 127 & 100 \\
Outliers & 27 & \\
Average value $(\mathrm{g}$ per $100 \mathrm{~g})$ & 1.92 & 1.96 \\
Range $(\mathrm{g}$ per $100 \mathrm{~g})$ & $0.55-3.66$ & $1.30-2.60$ \\
Standard deviation $(\mathrm{g}$ per $100 \mathrm{~g})$ & 0.57 & 0.34 \\
Relative standard deviation $(\%)$ & 29.5 & 17.2 \\
\hline
\end{tabular}

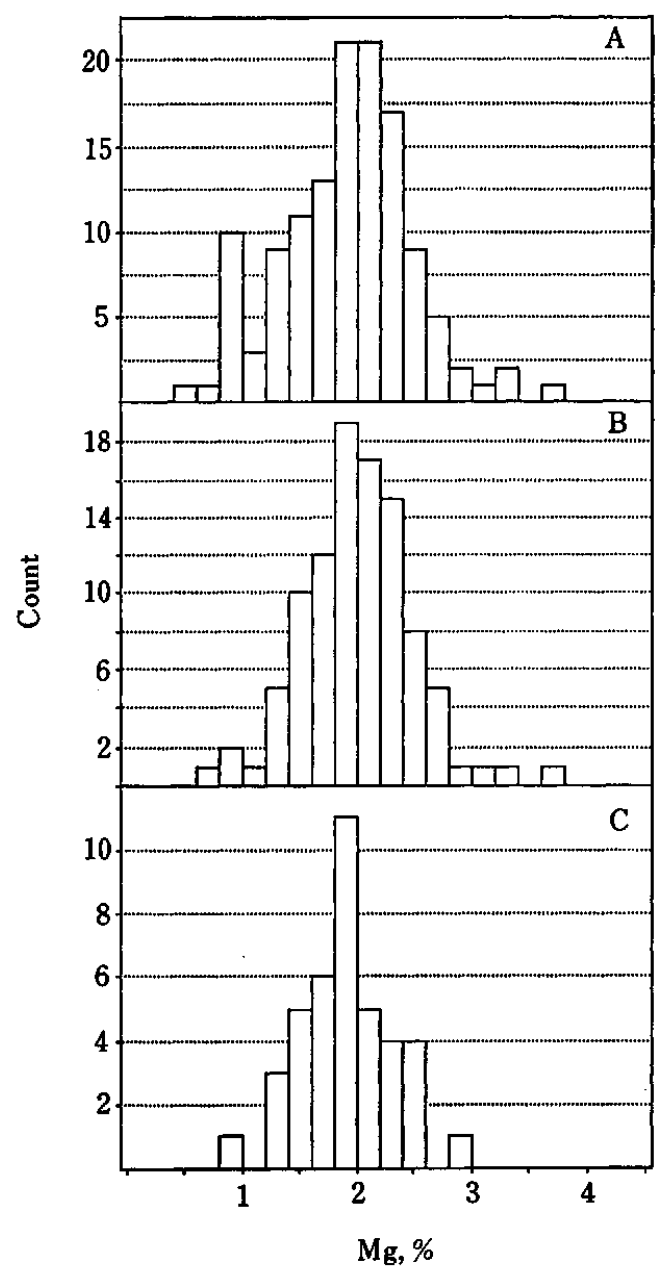

Fig. 4 Frequency distribution of the results obtained for magnesium: A, 127 initial results; $B, 99$ initial results obtained for samples of $1.0-3.5 \mathrm{mg}$ C, 40 results obtained in 10 determinations of magnesium.

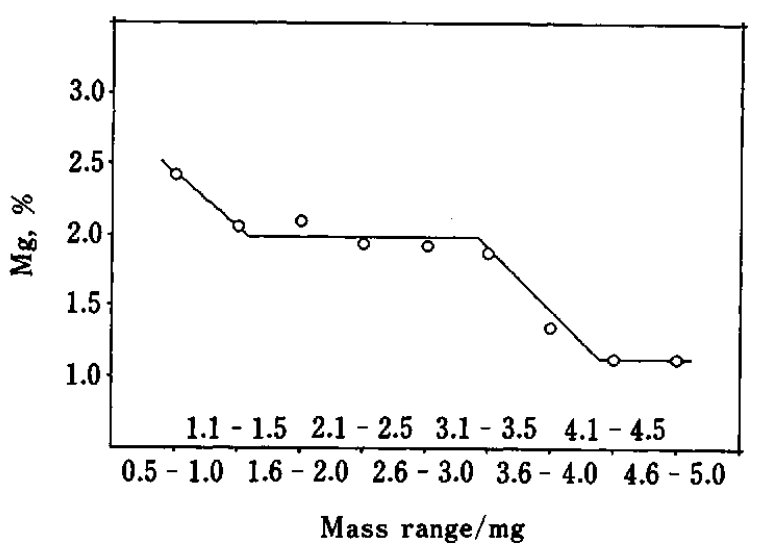

Fig. 5 Relationship between the magnesium content found and the amount of sample used.

experimental variables potentially affecting the determination of magnesium in the PVC sample, a total of 127 measurements were carried out by using eight calibration graphs. The results obtained are shown in Table 3. The average concentration found $(1.92 \%$ of $\mathrm{Mg})$ was quite consistent with the manufacturer's certified content and with that obtained by flame-AAS; however, the precision was rather poor ( $30 \%$ as RSD), as can be seen from the frequency distribution of results in Fig. 4A.

In previous work on the determination of metals in solid samples using GFAAS ${ }^{13,14}$, we found that the results to clearly depend on the amount of sample used. Thus, we checked for this effect on the determination of magnesium. For this purpose, the results obtained were distributed into groups of different sample mass ranges and an average value was calculated for each group. As respect. ${ }^{13}$ Figure 4B shows the frequency distribution for 99 results obtained with samples of $1.0-3.5 \mathrm{mg}$. smaller samples gave significantly higher magnesium contents; on the other hand, sample masses greater than $3.5 \mathrm{mg}$ provided lower magnesium contents. Magnesium behaves similarly to lead in PVC samples in this respect. ${ }^{13}$ Figure 4B shows the frequency distribution for 99 results obtained with samples of $1.0-3.5 \mathrm{mg}$.

We also investigated the potential improvement in precision obtained by increasing the number of measurements used in each determination. For this purpose, the results obtained for sample masses between 1.0 and $3.5 \mathrm{mg}$ were successively arranged in groups of one, two, three, and so on up to ten. An average value was calculated for each group and taken as the result for each determination; an overall average value was then obtained, together with its relative standard deviation.

Based on the results shown in Fig. 6, the average value obtained was virtually independent of the number of measurements used in each determination. The precision increased considerably from one to two measurements, but more gradually as the number was augmented; thus a point was reached where further increasing the number of measurements per determination no longer appropriate. The improvement, if 


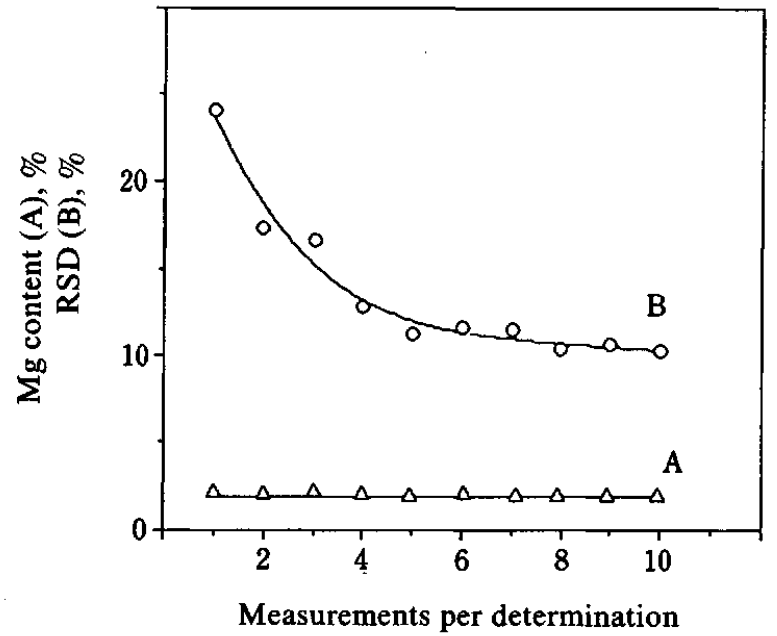

Fig. 6 Variation of the average magnesium content (A) and relative standard deviation (B) with the number of measurements carried out in each determination.

any, was negligible beyond 4 measurements.

The high RSD obtained can be partly ascribed to the presence of outliers arising from "nuggets" 26 or some other reason. As can be seen in Fig. 4B, some suspected values remained even if only the $1.0-3.5 \mathrm{mg}$ samples were considered. A large number of measurements allows values outside the interval $\bar{X} \pm 2 \sigma$ to be rejected, thereby significantly decreasing the RSD, as can be seen in Table 3.

Nevertheless, the number of measurements available to an analyst under normal conditions, is not too large (4 in this procedure), so it is very difficult to discard results reliably. Suspected results were rejected based on Dixon's Q-test. ${ }^{27}$

\section{Analysis of PVC samples}

A PVC sample was analyzed by using the proposed method. Based on the preliminary results, the sample mass used was between 1.0 and $3.5 \mathrm{mg}$, and four measurements were made for each determination. Figure $4 \mathrm{C}$ shows the frequency distribution for the 40 measurements performed. Dixon's test detected a single outlier that was thus excluded.

In order to compare the results obtained by direct analysis of the solid samples, measurements were also carried out by using flame-AAS after conventional sample treatment. The results obtained are shown in Table 4. Statistical tests revealed no significant differences $(p<0.05)$ between the average values provided by the two methods, yet the precision was significantly worse for the direct analysis of solids.

\section{Analysis time}

The time needed to carrying out the determination of magnesium in a real PVC sample under the optimal conditions was $c a .12 \mathrm{~min}$, so the resulting throughput is 5 samples $\mathrm{h}^{-1}$.
Table 4 Results obtained in the determination of magnesium by solid GFAAS and flame-AAS

\begin{tabular}{lcc}
\hline \multicolumn{1}{c}{ Parameter } & $\begin{array}{c}\text { Solid } \\
\text { GFAAS }\end{array}$ & $\begin{array}{c}\text { Flame- } \\
\text { AAS }\end{array}$ \\
\hline Number of determinations & 10 & 4 \\
Average value $(\mathrm{g}$ per $100 \mathrm{~g})$ & 1.95 & 1.92 \\
Range $(\mathrm{g}$ per $100 \mathrm{~g})$ & $1.77-2.16$ & $1.90-1.96$ \\
Standard deviation $(\mathrm{g}$ per $100 \mathrm{~g})$ & 0.13 & 0.03 \\
Relative standard deviation $(\%)$ & 6.4 & 1.4 \\
\hline
\end{tabular}

In conclusion, non-pulverulent solid samples can be readily introduced into a GFAAS atomizer through the central sampling hole of the graphite tube. Provided most of the matrix is eliminated during charring, the calibration with aqueous solutions is feasible. RSD values below $10 \%$ can be achieved by using an appropriate sample mass and making several measurements per determination. Also, using insensitive lines facilitates the determination of metals at concentration above $1 \%$.

In this way, magnesium at levels above $1 \%$ in PVC can be rapidly and conveniently determined without the need for any special equipment, thus making an appealing alternative to existing methods when expeditiousness is favored over precision.

This work was financially supported by the Dirección General de Investigación Científica y Técnica (DGICyT) of the Spanish Ministry of Education and Science Department, in the framework of Project PB93/0306.

\section{References}

1. M. Valcárcel and A. Ríos, Anal. Chem., 65, 781A (1993).

2. P. Esser, Fresenius' Z. Anal. Chem., 322, 677 (1985).

3. P. Esser, Fresenius' Z. Anal. Chem., 328, 410 (1987).

4. C. Bendicho and M. T. C. de Loos-Vollebregt, J. Anal. At. Spectrom., 6, 353 (1991).

5. U. Kurfürst, Fresenius' Z. Anal. Chem., 328, 316 (1987).

6. T. Hadeishi and R. McLaughlin, Fresenius' $Z$. Anal. Chem., 322, 657 (1985).

7. D. C. Baxter, J. Anal. At. Spectrom., 4, 415 (1989).

8. D. C. Baxter and W. Frech, Fresenius'J. Anal. Chem., 337, 253 (1990).

9. F. J. Langmyhr and G. Wibetoe, Prog. Anal. At. Spectrosc., 8, 193 (1985).

10. J. Y. Marks, G. G. Welcher and R. J. Spellman, Appl. Spectrosc., 31, 9 (1977).

11. Z. Grobenski, R. Lehmann, R. Tamm and B. Welz, Mikrochim. Acta, 1982 I, 115.

12. C. L. Chakrabarti, R. Karwowska, B. R. Hollebone and P.M. Johnson, Spectrochim. Acta, 42B, 1217 (1987).

13. M. A. Belarra, I. Lavilla, J. M. Anzano and J. R. Castillo, J. Anal. At. Spectrom., 7, 1075 (1992).

14. J. M. Anzano, M. P. Martínez-Garbayo, M. A. Belarra and J. R. Castillo, J. Anal. At. Spectrom., 9, 125 (1994).

15. A. Janßen, B. Brückner, K. H. Grobecker and U. Kurfürst, Fresenius' Z. Anal. Chem., 322, 713 (1985). 
16. G. R. Carnrick, B. K. Lumas and W. B. Barnett, J. Anal. At. Spectrom., 1, 443 (1986).

17. T. Nilsson and P. O. Berggren, Anal. Chim. Acta, 159, 381 (1984).

18. W. J. Rühl, Fresenius' Z. Anal. Chem., 322, 710 (1985).

19. U. Völlkopf, R. Lehmann and D. Weber, J. Anal. At. Spectrom., 2, 455 (1987).

20. P. O. Berggren, Anal. Chim. Acta, 119, 161 (1980).

21. A. G. Page, S. V. Godbole, M. J. Kulkarni, N. K. Porwal, S. S. Shelar and B. D. Joshi, Talanta, 30, 783 (1983).

22. F. E. Muñoz, A. Calvo and L. E. Leon, Anal. Lett., 16, 835 (1983).

23. Y. Koshino and A. Narukawa, Analyst [London], 117,
967 (1992).

24. M. A. Belarra, J. M. Anzano, F. Gallarta and J. R. Castillo, J. Anal. At. Spectrom., 2,77 (1987).

25. E. Lundberg and W. Frech, Anal. Chim. Acta, 104, 75 (1979).

26. U. Kurfürst, Pure Appl. Chem., 63, 1205 (1991).

27. J. C. Miller and J. N. Miller, "Statistics for Analytical Chemistry", pp. 60-61. Ellis Horwood, Chichester, 1984.

(Received February 24, 1995)

(Accepted April 26, 1995) 